\title{
The use of the 'wet workability limit' to predict the land quality 'workability' for some Uruguayan soils
}

\author{
A. Terzaghi ${ }^{1 *}$, W. B. Hoogmoed ${ }^{1}$ and R. Miedema ${ }^{2}$ \\ 'Soil Tillage Laboratory, Wageningen Agricultural University, Diedenweg 20, NL \\ $6703 \mathrm{GW}$ Wageningen, Netherlands \\ ${ }^{2}$ Department of Soil Science and Geology, Wageningen Agricultural University, \\ P.O. Box 37, NL 6700 AA Wageningen, Netherlands
}

Received 23 September 1986, accepted 14 October 1987

Key words: land evaluation, tillage, soil physical characteristics, workability, Uruguay

\begin{abstract}
In an attempt to predict the land quality 'workability', the upper critical moisture content for tillage is determined for some Uruguayan soils, using two laboratory methods developed for Dutch conditions ('upper tillage limit' or UTL, and 'wet workability limit' or WWL). The results obtained show that the critical point is mainly influenced by the percentage clay and organic matter $(\mathrm{OM})$ in the soil, yielding the linear relationship: $\mathrm{UTL}=7.75+1.91 \times \mathrm{OM}(\%)+0.34 \times$ clay $(\%)$. The UTL is highly correlated with the moisture content at a range of $\mathrm{pF}$ values between 2.0 and 2.7, this being a consequence of the influence of clay and organic matter on the shape of the pF curve. The results obtained by both methods (UTL and WWL) are highly correlated $(r=0.88)$. Within a certain range of texture, both methods yield statistically the same result.
\end{abstract}

\section{Introduction}

It is well known in agricultural practice that there is a critical moisture content above which the soils are too wet for successful tillage, i.e. for creating favourable conditions for plant growth with the least possible structure deterioration and with a low energy requirement. In land evaluation, this critical point is one of the tools used to quantify the land quality 'workability', especially when the land use arable farming, either under low or high mechanization levels, is considered. As definition we use: 'workability of a certain soil(type) indicates the possibilities for tillage of the soil under the given geographical and climatological conditions'.

\footnotetext{
* Present address: Ministerio de Agricultura y Pesca, Direccion de Suelos, Av. Garzón 456, Montevideo, Uruguay.
} 


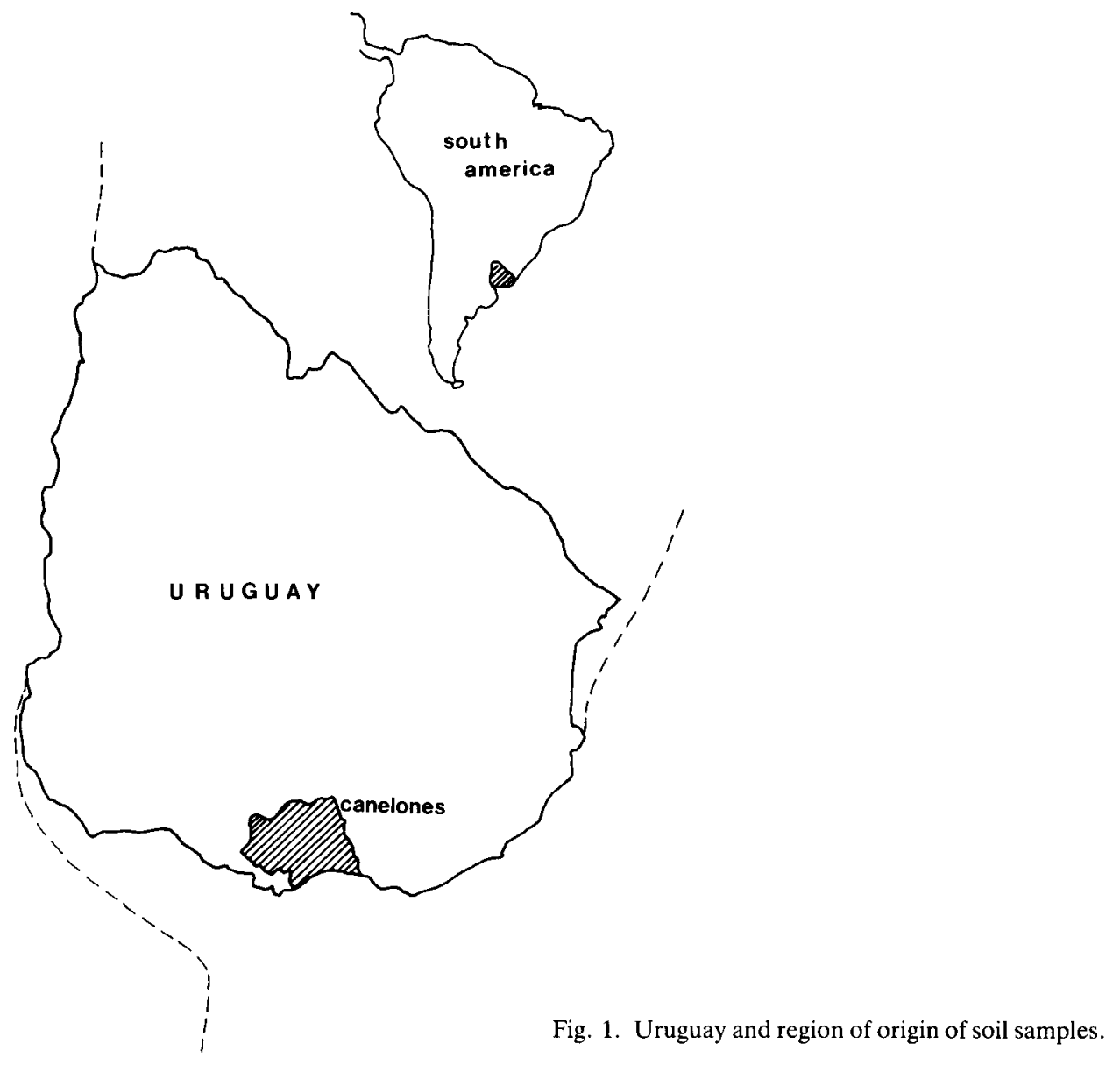

In our experiments, soils from Uruguay have been investigated. The country, shown in Fig. 1, is located in the southern hemisphere, between $30^{\circ}$ and $35^{\circ}$ latitude. All profiles have been collected in the department of Canelones, immediately to the north of Montevideo. It is an area of $4536 \mathrm{~km}^{2}$, which is $2.4 \%$ of the country's total.

Fig. 2 shows the distribution of the mean monthly rainfall and the mean monthly temperatures in the southern part of the country. The two cropping periods are also presented. The most common winter crops are wheat and barley, while the principal summer crops are sorghum and maize. Rotations include 2 or 3 years of arable farming, followed by 2 to 5 years of pasture, but on some farms arable cropping is virtually continuous. Tillage is performed either after the wet winter in preparation of a summer crop, or in early autumn when after the harvest of the summer crop, a winter crop follows in the rotation. For the tillage operations in spring, the soil is still wet, because although rainfall is low in the actual winter period, the evapora- 


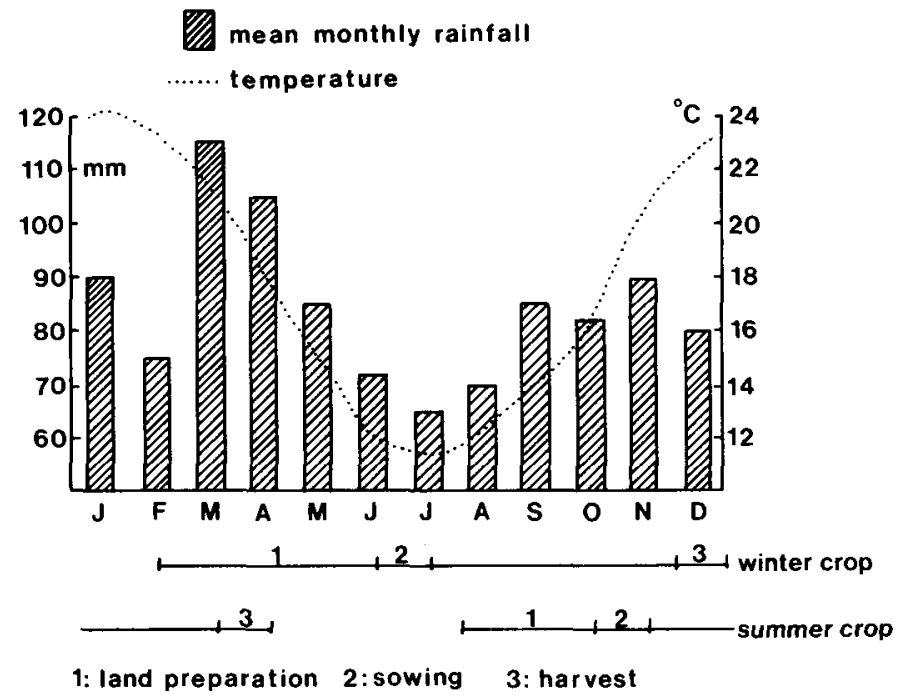

Fig. 2. Some climatic data of the area, including a cropping calender. Source: Atlas climatologico del Uruguay, 1978. Facultad de Agronomia, Montevideo (Uruguay).

tion rates are also very low. The autumn operations are in the onset of the rainy period. In general, there is no possibility for artificial drainage in the country and this, together with the very irregular and unpredictable pattern of the rainfall, makes it important to know the workable periods well.

With respect to the implements available in this area, mainly moldboard and disk plows are used for primary tillage, although in recent years, chisel plowing has become an alternative practice. For secondary tillage, disk and tooth harrows are most commonly used. The workability range is different for each of these implements, but in general primary-tillage implements can be used under somewhat wetter conditions than harrows. However, under strong drying conditions the topsoil may be dry enough for tillage, while the subsoil is still too wet to bear the load of the tractor and equipment.

For a long time, the Atterberg limits (Atterberg, 1911a and b) have been used to define the moisture range within which it is possible to perform tillage operations. A serious drawback in this method is the use of plastic soil in which the original structure has already been destroyed completely by kneading, while with the workability tests the resistance of the aggregates against a kneading action is tested. Also the subjectivity in the judgement of the limit may prove a drawback.

In the present study, two Dutch methods for the determination of the critical moisture content of the soil at the wet side of the range are tried out. The first one, the microtillage test (Koenigs, 1976) defines one critical value rather than a range and this has been the main reason for its selection. It is based on the hypothesis that the effects of the large forces exerted by the machinery during a short period of time 
A. TERZAGHI, W. B. HOOGMOED AND R. MIEDEMA

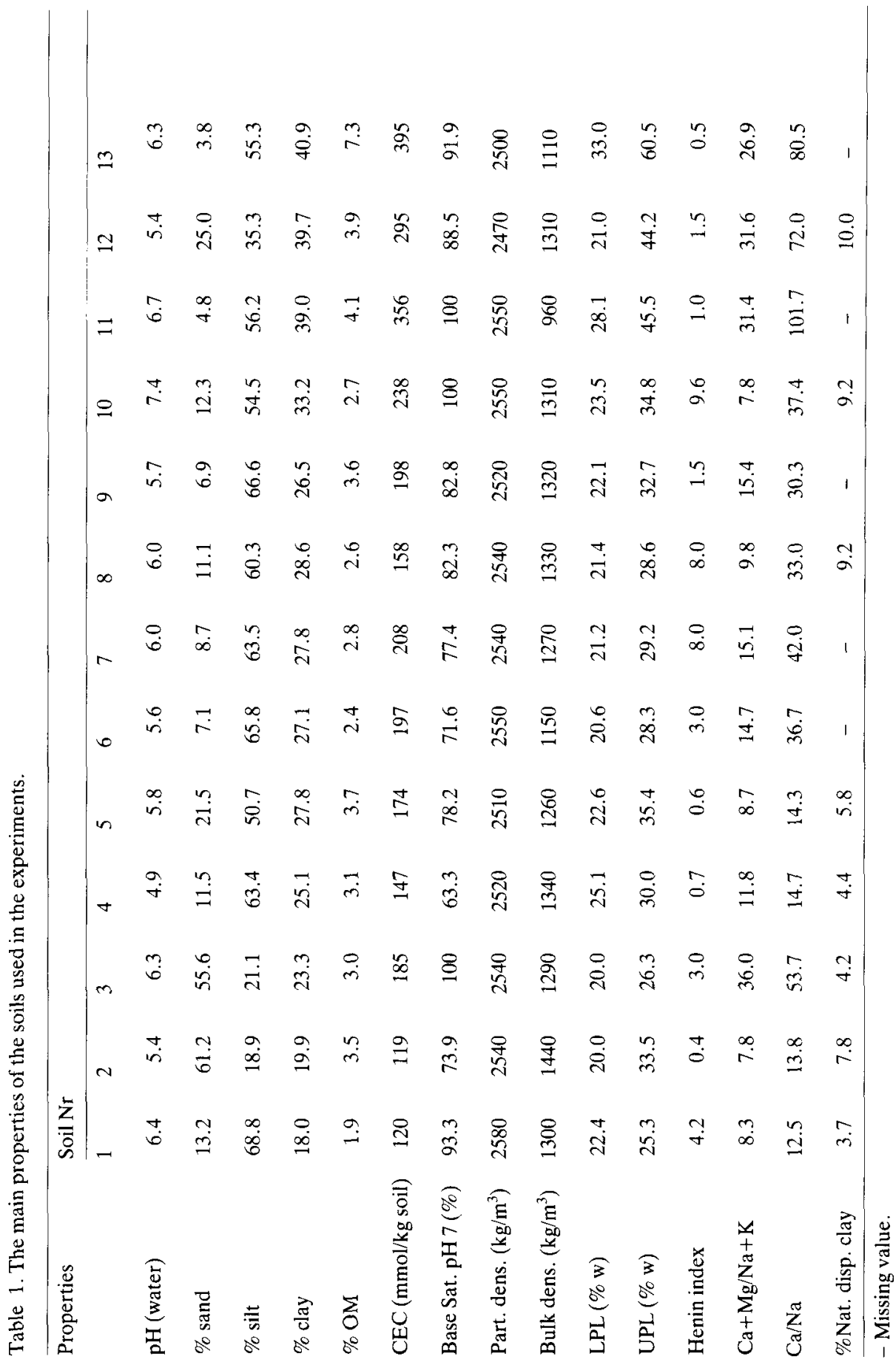


can be simulated by the repeated and slow application of a far smaller force. Visual inspection and energy requirement determine the critical value. The results of visual observations can be quantified by drying and sieving. The second method was developed by Perdok et al. (Perdok, Klooster \& Sprong, 1973, internal report) and measures the air permeability of a series of samples with increasing moisture contents under different degrees of loading. This method was included, because it offers (once calibrated) an objective means of determining the critical moisture point. Both methods have proven to be in agreement with each other as both were calibrated by the moisture contents at which keen farmers start spring harrowing. At that moment the fields have been sampled by Perdok. The methods have also been used in Kenya, though of course not on the same soils (Kauffman, 1975; Ellen, 1986). Use of the air permeability method in Portugal is reported by Kouwenhoven (1981).

\section{Methods and materials}

\section{Soils}

The major part of the department of Canelones is included in the unit Vp4-3a on the soil map of the world, scale 1:5000 000 (FAO-Unesco, 1971). Pellic Vertisols are the dominant soils with Luvic Phaeozems and Mollic Planosols as associated soils (FAO-Unesco, 1974). A small part belongs to the Re1-1b unit, with coarse-textured Eutric Regosols as dominant soils. The soils used in this experiment are predominantly Phaeozems; soils with a mollic A horizon and in some cases an argillic B horizon. The soil moisture regime is udic. They are soils with a high natural fertility, and with a good moisture storage capacity, suitable for arable farming and grassland. The main problems are the poor internal drainage because of the argillic $\mathrm{B}$ horizon and the risk for water erosion in years with heavy rainfall because of the topography (slopes ranging between 1 and $8 \%$ ). In general, the soils originate from sediments deposited over older sedimentary or igneous rocks. Only in places where the youngest sediment deposit is very thin, some influence of the underlying material on the topsoil properties occurs. Table 1 gives a summary of the main soil properties for the 14 profiles under study. More detailed information on these soils is given by Sganga (1982a, b).

\section{Microtillage test}

This laboratory method (Koenigs, 1976) is based on simulating the effects of tillage on a micro-scale. From each soil the $2-4 \mathrm{~mm}$ aggregate fraction is separated by sieving. Twenty grams are placed into stainless steel saucers $7 \mathrm{~cm}$ wide and tapped into dense packing with a tightly nailed plank. A series of moisture contents with steps of $2 \%$ is made by wetting dropwise from a graduated pipette. After covering and equilibration overnight, the test can proceed. Tillage is simulated by drawing a hammer with a beveled head (area $360 \mathrm{~mm}^{2}$, weight $180 \mathrm{~g}$ ) eighty times over the surface, avoiding pressure and turning the saucer after each stroke. Soil sticking to the hammer is scraped off against the rim. Grading of the result is done by sight and by measuring the force needed to draw a spatula, $9 \mathrm{~mm}$ wide, through the sample. 
The thickness, $d$, of the soil layer is also measured. The moisture content is determined after the test. Thus the moisture content at which the aggregates get smeared and the pull increases sharply is found. The moisture content $1 \%$ below that level is considered to be the maximum moisture content for spring tillage, the upper tillage limit (UTL). The pull of the spatula can be converted into shear strength (in $\mathrm{N} / \mathrm{mm}$ ) by the formula

$$
\tau_{\mathrm{w}}=\text { force } \times 252.6 / d
$$

with force representing the pull (in N) and $d$ the thickness (in $\mathrm{mm}$ ) of the soil layer.

\section{Air permeability test}

This test is based on the hypothesis that during spring cultivations in the Netherlands the main cause of damage is the compaction of the soil due to traffic. So, basically the susceptibility for compaction (measured by air permeability) is determined (Perdok, Klooster \& Sprong, internal report).

The same size of aggregates as in the previous method is used. Portions of $75 \mathrm{~g}$ are spread evenly in a layer of $1 \mathrm{~cm}$, moistened to the same range and in the same way as used with the previous method. The soil is covered and kept overnight to equilibrate. Next day the samples are filled carefully into sample rings of $100 \mathrm{~cm}^{3}$ (diametre $5 \mathrm{~cm}$; height $5 \mathrm{~cm}$ ). The rings were closed at the bottom by a piece of cheese cloth. Each sample is subsequently given 10,20,30 and $40 \mathrm{MPa}$ compression using a laboratory press. For each compaction level, the air permeability is determined by means of a permeameter (Perdok \& Hendrikse, 1982). According to Kmoch (1962), for the given experimental conditions, the intrinsic air permeability $K_{\mathrm{i}}\left(\mu \mathrm{m}^{2}\right)$ can be calculated from

$$
K_{\mathrm{i}}=a \times p \times t^{-1}
$$

with $a=$ calculation factor (for this case $6.469 \times 10^{-3} \mathrm{~mm} \cdot \mathrm{sec}$ ), $l=$ height of soil sample $(\mathrm{mm})$ and $t=$ time necessary for the air to pass through the sample (s).

For each sample, the moisture content is determined. For Dutch conditions, the wet workability limit (WWL) can be defined as the moisture content of a soil at which, after a compression of $40 \mathrm{MPa}$, the intrinsic air permeability has decreased to a value of $1 \mu \mathrm{m}^{2}$.

\section{Other characteristics}

A pF curve (moisture content at various suction levels) was determined for the aggregates of each soil, using sand, sand-kaolin beds and pressure plate equipment. The most important values are given in Table 2 . Though the two methods look rather different, they agree so far as with both methods compressive and shearing forces are used. No effective compression is possible without shearing and flow.

Analysis

The results obtained from both methods are compared with each other and rela- 
Table 2. Some important $\mathrm{pF}$ values of the soil aggregates $(\% \mathrm{w})$.

\begin{tabular}{lllllll}
\hline Soil Nr & \multicolumn{7}{l}{$\mathrm{pF}$ value } & \multicolumn{5}{l}{} \\
\cline { 2 - 7 } & 2.0 & 2.25 & 2.5 & 2.7 & 2.75 & 3.0 \\
& & & & & & \\
1 & 24.2 & 22.0 & 19.3 & 17.0 & 16.9 & 14.2 \\
2 & 22.2 & 21.0 & 20.0 & 19.0 & 18.8 & 17.4 \\
3 & 22.8 & 21.7 & 20.2 & 19.2 & 19.0 & 17.6 \\
4 & 28.6 & 28.0 & 27.1 & 25.7 & 25.7 & 23.1 \\
5 & 28.0 & 27.1 & 25.8 & 24.5 & 24.0 & 22.0 \\
6 & 27.5 & 26.7 & 25.7 & 25.0 & 24.2 & 22.5 \\
7 & 26.5 & 26.0 & 25.1 & 24.5 & 24.2 & 23.0 \\
8 & 22.1 & 21.9 & 21.4 & 21.0 & 20.9 & 20.0 \\
9 & 27.9 & 27.1 & 26.2 & 25.5 & 25.2 & 23.8 \\
10 & 27.0 & 26.4 & 25.8 & 25.0 & 24.9 & 23.8 \\
11 & 33.0 & 32.1 & 31.0 & 30.0 & 29.9 & 28.6 \\
12 & 30.0 & 29.2 & 28.5 & 27.5 & 27.4 & 26.0 \\
13 & 42.0 & 40.9 & 39.5 & 38.4 & 38.0 & 36.0 \\
\hline
\end{tabular}

tionships are determined. A comparison is also made with the moisture content at a number of $\mathrm{pF}$ values, to check whether the critical point can be defined in terms of a certain $\mathrm{pF}$ value. The available particle size distribution and chemical and physical data of the soils are used to carry out a multiple regression to determine how much certain soil properties contribute to the explanation of the critical point.

\section{Results}

The values for both methods, expressed in moisture content (on weight basis) are presented in Table 3. In Figs 3 and 4, some examples of the determination proce-

Table 3. Workability limits obtained by the microtillage (UTL) and the air permeability (WWL) method. Moisture content of soil in percent (weight).

\begin{tabular}{lll}
\hline Soil Nr & UTL & WWL \\
1 & 19.0 & 23.8 \\
2 & 18.5 & 18.6 \\
3 & 20.0 & 20.0 \\
4 & 27.3 & 28.2 \\
5 & 23.5 & 22.4 \\
6 & 23.5 & 20.5 \\
7 & 23.2 & 21.6 \\
8 & 19.9 & 22.2 \\
9 & 23.0 & 24.8 \\
10 & 22.0 & 20.9 \\
11 & 29.5 & 26.7 \\
12 & 29.0 & 25.5 \\
13 & 36.3 & 33.2 \\
\hline
\end{tabular}




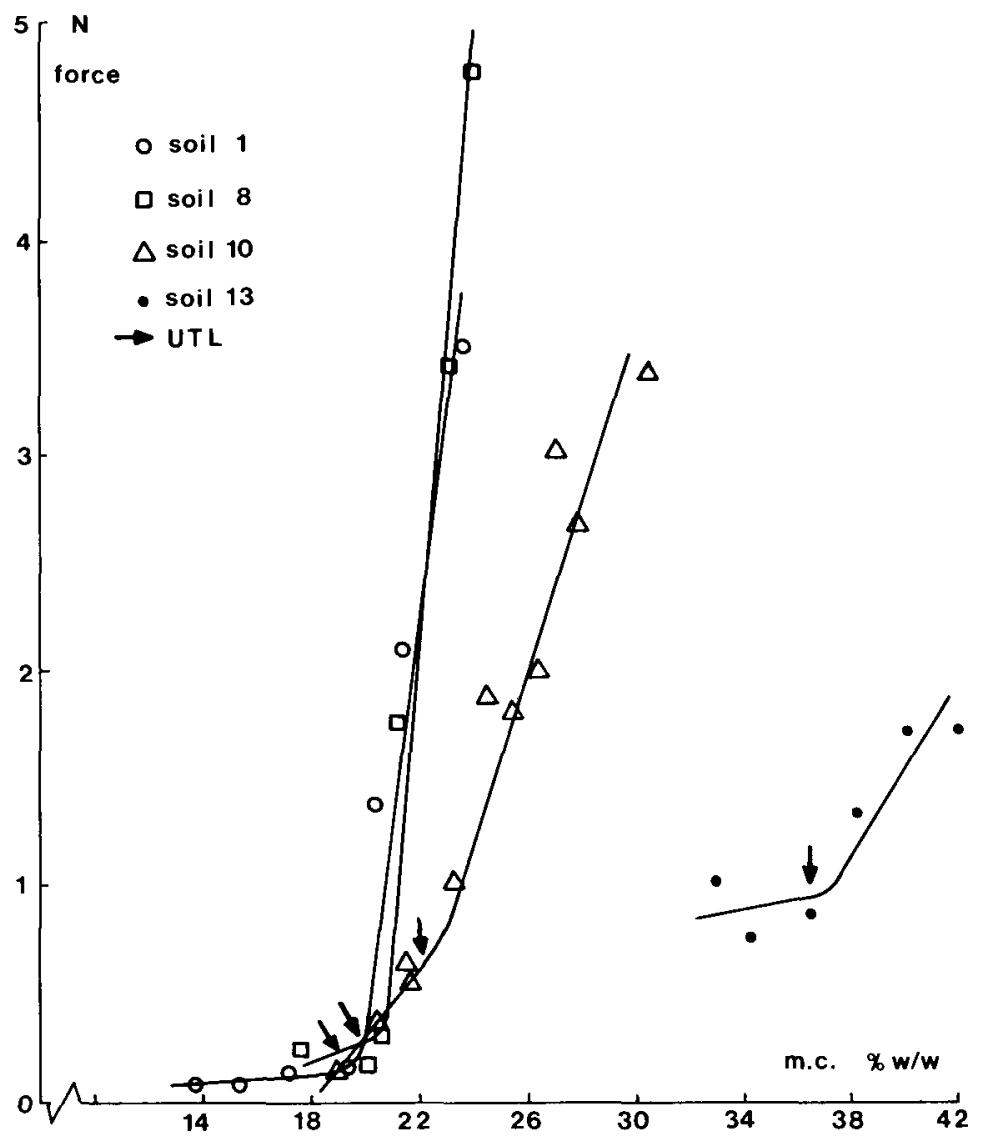

Fig. 3. Force (to move spatula) vs. moisture content to determine UTL in the microtillage test.

dure are given for two extreme soils (Nrs 1 and 13) and for two intermediate soils (Nrs 8 and 10). For the microtillage test, visual observations were also made during the test procedure. An example is given in Table 4, showing that there is a clear coincidence of the sharp increase in pull with the caking and smearing of the soil.

\section{Discussion}

The results obtained by both methods are compared and the linear correlation coefficient between both sets of data is calculated. The value $r$ was found to be 0.88 , which means significant at the $0.1 \%$ level, so both sets of data follow the same trend (see Fig. 5). It is important to know whether the same results are obtained by both methods or not. This means that the null hypothesis to be tested is that the regression line (dotted line in Fig. 5) goes through the origin. This null hypothesis is 


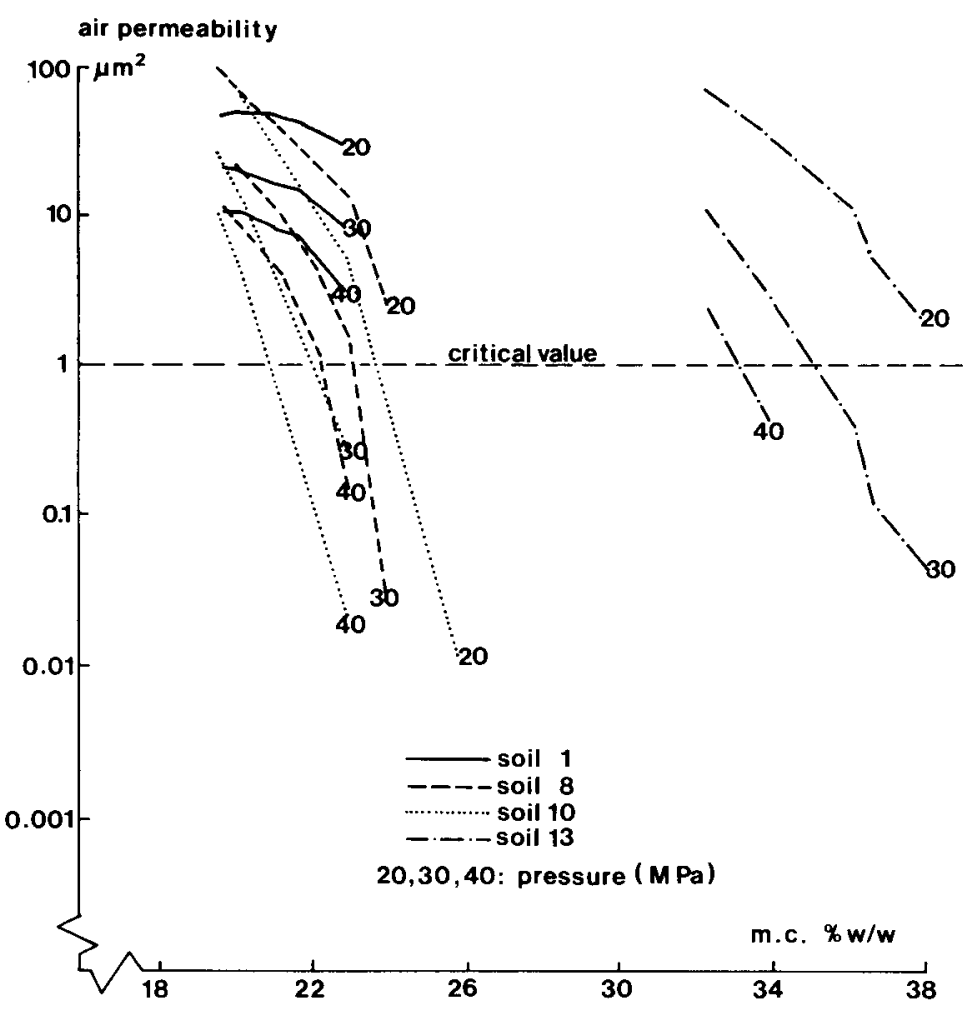

Fig. 4. Air permeability (logarithmic scale) vs. moisture content to determine WWL in air permeability test.

tested according to Snedecor \& Cochran (1980). When all soils were considered, this null hypothesis had to be rejected at the $5 \%$ level. When four soils with the highest and lowest clay content (Nrs 1, 11, 12 and 13) are left out, statistically the same result is obtained by both methods, within a certain range of clay content (19.9 to $33.2 \%$ ).

A comparison is also made between UTL and the moisture content at various $\mathrm{pF}$ values (determined for each soil). The results of these fits are shown in Table 5. Nearly all pF values in the range 2.0-3.0 give a very good correlation $(r=0.96$ or higher). For the WWL values, there also is a correlation, but not as strong, $r$ ranged between 0.80 and 0.86 for $\mathrm{pF}$ values between 2.0 and 2.75 (see Table 5).

To see the influence of some soil properties on the UTL, a multiple regression was conducted using SPSS (Nie et al, 1975). Information was available on properties given in Table 1 and on percentage naturally dispersed clay, the Henin index for structural stability, the ratio bivalent/monovalent cations in the exchange complex and the $\mathrm{Ca} / \mathrm{Na}$ ratio in the exchange complex. Of all these, only the clay percentage and the organic matter content had a significant effect, explaining $87 \%$ of the vari- 


\section{A. TERZAGHI, W. B. HOOGMOED AND R. MIEDEMA}

Table 4. Example of visual examination of soil structure during microtillage test.

\begin{tabular}{|c|c|c|c|c|c|c|c|c|c|c|}
\hline \multirow{2}{*}{$\begin{array}{l}\text { Soil } \\
\mathrm{Nr}\end{array}$} & \multirow{2}{*}{$\begin{array}{l}\text { m.c. } \\
(\% \mathrm{w})\end{array}$} & \multirow{2}{*}{$\begin{array}{l}\mathrm{d} \\
(\mathrm{mm})\end{array}$} & \multirow{2}{*}{$\begin{array}{l}\mathrm{F} \\
(\mathrm{N})\end{array}$} & \multirow{2}{*}{$\begin{array}{l}\tau \\
(\mathrm{N} / \mathrm{mm})\end{array}$} & \multirow{2}{*}{$\begin{array}{l}S \\
(g)\end{array}$} & \multicolumn{5}{|c|}{ Visual observations (after . . . strokes) ${ }^{*}$} \\
\hline & & & & & & 20 & 40 & 60 & 80 & final \\
\hline 8 & 17.7 & 8.8 & 0.241 & 6.92 & 0.20 & -- & -- & -- & -- & G \\
\hline 8 & 20.0 & 8.6 & 0.194 & 5.70 & 0.15 & -- & -- & -- & -- & $\mathrm{G}$ \\
\hline 8 & 20.6 & 7.6 & 0.320 & 10.64 & 0.78 & -- & -- & -- & $--c$ & $\mathrm{G}$ \\
\hline 8 & 21.2 & 6.1 & 1.764 & 73.05 & 2.01 & -- & $--c$ & $--c$ & $\mathrm{ccr}$ & B \\
\hline 8 & 23.1 & 5.3 & 3.428 & 163.38 & 6.29 & $--c$ & $\mathrm{cc}$ & $\mathrm{cc}$ & $\mathrm{ccz}$ & B \\
\hline 8 & 23.8 & 5.4 & 4.795 & 222.90 & 2.33 & $\mathrm{cc}$ & $\mathrm{ccz}$ & $\mathrm{ccz}$ & $\mathrm{ccz}$ & B \\
\hline 10 & 19.0 & 9.6 & 0.169 & 4.45 & 0.09 & - & -- & -- & -- & G \\
\hline 10 & 20.4 & 10.2 & 0.360 & 8.92 & 0.83 & - & -- & -- & -- & $\mathrm{G}$ \\
\hline 10 & 21.4 & 10.1 & 0.643 & 16.08 & 3.14 & -- & $--+s$ & $--+s$ & $--+s$ & $G$ \\
\hline 10 & 21.6 & 9.8 & 0.557 & 14.36 & 3.39 & -- & --+ & $--+s$ & $--+\mathrm{sr}$ & G \\
\hline 10 & 23.2 & 8.0 & 1.019 & 32.17 & 5.12 & --+ & $--+s$ & $--+\operatorname{css}$ & $--+\operatorname{css}$ & $\mathrm{B}$ \\
\hline 10 & 24.5 & 7.8 & 1.888 & 61.14 & 4.87 & --+ & $--+s s$ & $+\operatorname{css}$ & $+\operatorname{css}$ & B \\
\hline 10 & 25.4 & 7.7 & 1.834 & 60.16 & 11.55 & --+ & --+ & $+\operatorname{css}$ & $+\operatorname{css}$ & B \\
\hline 10 & 26.4 & 8.5 & 2.024 & 60.15 & 8.51 & --+ & --+ & $+\operatorname{css}$ & $+\operatorname{css}$ & B \\
\hline 10 & 27.0 & 10.2 & 3.039 & 75.26 & 9.15 & $--+s$ & $++s s$ & $++s s$ & $++s s$ & B \\
\hline 10 & 27.8 & 9.2 & 2.695 & 74.00 & 7.18 & $++s s$ & $++\operatorname{css}$ & $\operatorname{ccss}$ & $\operatorname{ccss}$ & B \\
\hline 10 & 30.4 & 5.2 & 3.399 & 165.10 & 16.64 & $++s s$ & $++s s$ & $++s s$ & $++s s$ & B \\
\hline
\end{tabular}

* Meaning of symbols:

d Depth layer soil in saucer after tillage $(\mathrm{mm})$

F Reaction force to spatula (N)

$\tau \quad$ Resulting shear strength (see text)

$\mathrm{S} \quad$ Weight of soil sticking to saucer $(\mathrm{g})$

- No change in structure observed

- - Some aggregates are reduced in size, others remain unchanged

- - - Practically all aggregates reduced in size

$+\quad$ Some aggregates stick together forming bigger structural units

++ Most of the aggregates stick together

c Part of the sample cakes at bottom of saucer

cc Most of the sample cakes

s Some stickiness to saucer and/or hammer

ss Serious stickiness to saucer and/or hammer

r Rough surface

m Smooth surface

z smearing

G good

B bad

ation $\left(r^{2}=0.87\right)$. The linear relationship obtained is:

$$
\mathrm{UTL}=7.75+1.91 \mathrm{OM}(\%)+0.34 \text { clay }(\%)
$$

The cementing soil constituents clay and organic matter adsorb most of the added water because of their high specific surface area. For clay, the water adsorption 


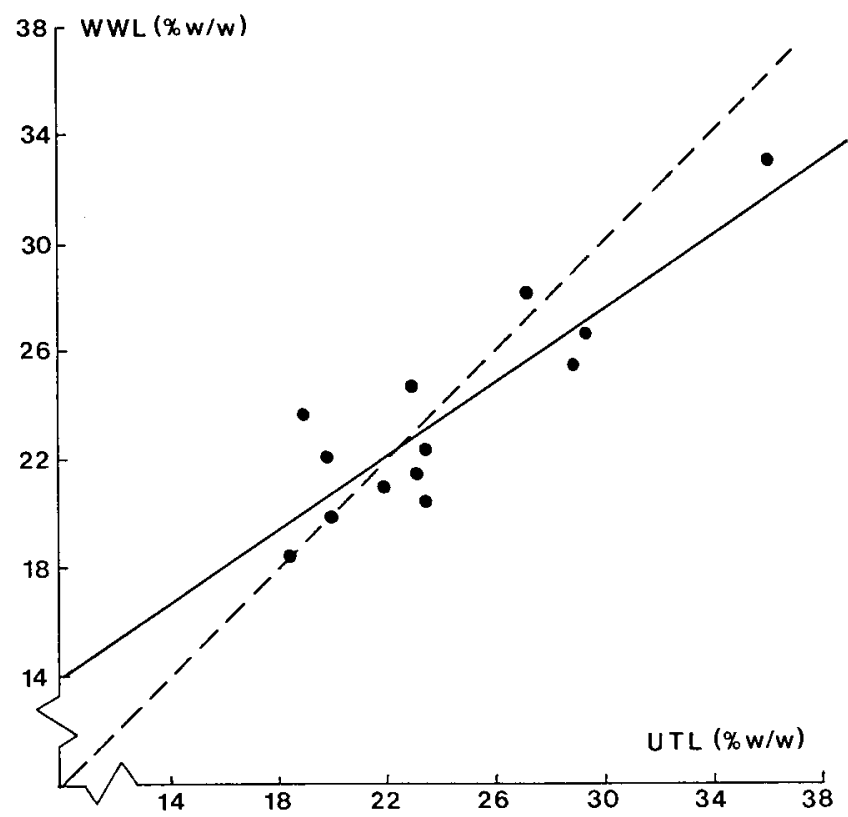

Fig. 5. Linear regression line between UTL and WWL values for 13 soils.

leads to larger distances between the clay plates, the swelling. Thus their cohesion is weakened and especially their resistance against transversal forces (pack of cards). The bonds by organic matter limit the swelling, so extra water is required to reduce this cohesion. The larger the clay and organic matter content of a soil, the larger its specific surface area is, and the more water must be added to increase the internal distances or swelling pressures to a point where tillage causes smearing. Consequently, the UTL increases in both cases. For Dutch soils Koenigs (1976) found the relationship:

$$
\mathrm{UTL}=0.34 \text { clay }(\%)+1.55 \mathrm{OM}(\%)
$$

which shows that there is a similar trend in relationship between the UTL and the two parameters.

Since the Atterberg consistency limits LPL (lower plastic limit) and UPL (upper plastic limit) were also available (see Table 1), the correlation between these characteristics was determined. There was a very good correlation between the LPL and both UTL and WWL; $R$-values (see Table 5) are 0.83 and 0.87 respectively. The correlation between UPL and both tillage limits was also good ( $R$ being 0.88 and 0.74 ), but probably less interesting since only LPL is closely linked to a workability limit. 
Table 5. Summary of the various fits between UTL, WWL, LPL, clay and OM, and $\mathrm{pF}$ values (13 soils used).

\begin{tabular}{|c|c|c|}
\hline & Perc. ${ }^{a}$ & $R^{\mathrm{b}}$ \\
\hline $\mathrm{WWL}=14.56+0.10$ clay $+1.86 \mathrm{OM}$ & 48.1 & 0.75 \\
\hline $\mathrm{UTL}=7.75+0.34$ clay $+1.91 \mathrm{OM}$ & 78.4 & 0.91 \\
\hline $\mathrm{UTL}=-1.415+0.921 \mathrm{pF} 2.0$ & 91.5 & 0.96 \\
\hline $\mathrm{UTL}=-0.677+0.924 \mathrm{pF} 2.25$ & 93.2 & 0.97 \\
\hline $\mathrm{UTL}=0.677+0.911 \mathrm{pF} 2.5$ & 93.2 & 0.97 \\
\hline $\mathrm{UTL}=2.209+0.887 \mathrm{pF} 2.7$ & 90.6 & 0.96 \\
\hline $\mathrm{UTL}=2.175+0.898 \mathrm{pF} 2.75$ & 91.4 & 0.96 \\
\hline $\mathrm{UTL}=4.191+0.873 \mathrm{pF} 3.0$ & 86.8 & 0.96 \\
\hline$W W L=5.707+0.647 \mathrm{pF} 2.0$ & 72.3 & 0.86 \\
\hline $\mathrm{WWL}=6.542+0.638 \mathrm{pF} 2.25$ & 70.7 & 0.85 \\
\hline $\mathrm{WWL}=7.914+0.612 \mathrm{pF} 2.5$ & 66.5 & 0.83 \\
\hline$W W L=9.339+0.580 \mathrm{pF} 2.7$ & 60.7 & 0.80 \\
\hline$W W L=9.165+0.593 \mathrm{pF} 2.75$ & 62.7 & 0.81 \\
\hline$W W L=10.953+0.557 \mathrm{pF} 3.0$ & 54.8 & 0.76 \\
\hline $\mathrm{UTL}=-2.5088+1.1262 \mathrm{WWL}^{\mathrm{c}}$ & 75.5 & 0.88 \\
\hline $\mathrm{UTL}=-2.1845+1.1399 \mathrm{LPL}$ & 66.2 & 0.83 \\
\hline$W W L=2.0850+0.9345 \mathrm{LPL}$ & 73.7 & 0.87 \\
\hline $\mathrm{UTL}=-3.4831+1.1819 \mathrm{LPL}^{\mathrm{c}}$ & 52.6 & 0.77 \\
\hline$W W L=-7.7424+1.3684 \mathrm{LPL}^{\mathrm{c}}$ & 60.7 & 0.81 \\
\hline $\mathrm{UTL}=8.3584+0.4535 \mathrm{UPL}$ & 75.1 & 0.88 \\
\hline$W W L=13.3203+0.2977 \mathrm{UPL}$ & 50.3 & 0.74 \\
\hline
\end{tabular}

${ }^{a}$ Perc. = percentage of variance accounted for (= difference between residual and total mean squares, as percentage of total mean squares).

${ }^{b} R=$ root of $R^{2}$ (= difference between residual and total sum of squares, as ratio of total sum of squares).

c Only 9 soils used (see text).

\section{Conclusions}

1. The land quality 'workability', expressed as the upper tillage limit, depends mainly on clay and organic matter content of the soil.

2. The pF curve is a very important characteristic of the soil, since the UTL is closely related to a range of $\mathrm{pF}$ values. This is easily understood since moisture content at these $\mathrm{pF}$ values is also highly influenced by the same soil characteristics mentioned under 1 .

3. The results obtained by the method of Koenigs (1976) are highly correlated with the method by Perdok et al. so both seem to be suitable to predict the critical upper moisture content for tillage. Within a certain range of texture (19.9 to $33.2 \%$ clay) they yield the same results for the soils under study. To find a relationship between the methods outside this range, more experiments are required. 
4. While the correspondance between both methods for the complete range of soils is not determined, the method of Koenigs is preferred because it allows an additional visual judgement of the results when the simulated tillage is performed. However, once both methods are in agreement, the method of Perdok et al. has the advantages of being objective, quicker and more precise.

5. The major requirement for further research is the link between the laboratory data and the field 'truth'. As Dutch conditions are different from Uruguayan, the experience of farmers is needed to support the experiments. Especially for the heavier soils, it is necessary to gain quantitative information on the dry side of the workable range as well, since the power requirements will increase steeply on drying.

\section{References}

Atterberg. A., 191 la. Über die physikalische Bodenuntersuchung. Internationale Mitteilungen für Bodenkunde 1: 7-9.

Atterberg, A., 1911b. Die Plastizität der Tone. Internationale Mitteilungen für Bodenkunde 1: 10-43.

Ellen, H., 1986. Workability of some Kenyan soils. Soil \& Tillage Research 8: 367-368.

FAO-UNESCO, 1971. Soil map of the world 1:5000 000. Vol. IV: South America. FAO-UNESCO, Rome, Italy, $193 \mathrm{pp}$.

FAO-UNESCO, 1974. Soil map of the world 1:5000 000. Vol. I: Legend. FAO-UNESCO, Rome, Italy, $59 \mathrm{pp}$.

Kauffman, J. H., 1975. Tillage properties of the Kapenguria soils and some other soils in Kenya, as examined with the microtillage test. M.Sc. thesis Agricultural University Wageningen. Department of Soil Science and Geology, $62 \mathrm{pp}$.

Koenigs, F. F. R., 1976. Determination of the Upper Tillage Limit for spring tillage by a laboratory test. Proceedings 7th Conference of the International Soil Tillage Research Organisation, Uppsala (Sweden). Agricultural College of Sweden, Division of Soil Management Report Nr 45, p. 19:1-19:6.

Kmoch, H. G., 1962. Die Luftdurchlässigkeit des Bodens, ihre Bestimmung und ihre Bedeutung für einige ackerbauliche Probleme. Bornträger, Berlin, $90 \mathrm{pp}$.

Kouwenhoven, J. K., 1981. Tillage and mechanization in Leziria Grande de Vila Franca de Xira, Portugal. Agricultural Mechanization in Asia, Vol. XII (2), p. 17-22.

Nie, N. H., C. H. Hull, J. G. Jenkins, K. Steinbrenner \& D. H. Brent, 1975. SPSS: Statistical package for the social sciences, 2nd ed. McGraw-Hill, New York, $675 \mathrm{pp}$.

Perdok, U. D. \& L. M. Hendrikse, 1982. Workability test procedure for arable land. Proceedings of the 9 th Conference of the International Soil Tillage Research Organisation. Agricultural Institute Osijek (Yugoslavia), p. 511-519.

Sganga, J. C., 1982a. Los relevamientos de suelos del Uruguay con el enfoque particular de los suelos de Canelones. Boletin Tecnico del MAP. Ministerio de Agricultura y Pesca, Montevideo, Uruguay.

Sganga, J. C., 1982b. Carta preliminar de reconocimiento de suelos del Uruguay, departemento de Canelones, escala 1:100 000. Ministerio de Agricultura y Pesca, Montevideo, Uruguay.

Snedecor, G. W. \& W. G. Cochran, 1980. Statistical methods, 7th ed. Iowa State University Press. Ames, Iowa (USA), p. 172-174. 